\title{
Formation mechanism for the amplitude of interannual climate variability in subtropical northern hemisphere: relative contributions from the zonal asymmetric mean state and the interannual variability of SST
}

\author{
Chao $\mathrm{He}^{1,2} \cdot$ Ailan $\mathrm{Lin}^{1} \cdot$ Dejun $\mathrm{Gu}^{1} \cdot$ Chunhui $\mathrm{Li}^{1} \cdot \operatorname{Bin}$ Zheng ${ }^{1}$
}

Received: 17 December 2015 / Accepted: 27 March 2016 / Published online: 6 April 2016

(C) The Author(s) 2016. This article is published with open access at Springerlink.com

\begin{abstract}
The Amplitude Interannual climate Variability (AIV) differs among the subtropical northern hemisphere, and the Western North Pacific (WNP) was claimed to exhibit the largest AIV. The robustness of the AIV pattern is investigated in this study with different atmospheric variables from multiple datasets. As consistently shown by the interannual variance patterns of precipitation and circulation, the AIV over subtropical northern hemisphere closely follows the mean state of precipitation, where higher (lower) AIV is located at moister (drier) regions. The largest AIV is seen over the broad area from South Asia to WNP, followed by a secondary local maximum over the Gulf of Mexico. To further investigate the formation mechanism for the AIV pattern, numerical simulations are performed by Community Atmosphere Model version 4 (CAM4). The zonal asymmetry of AIV is reduced if the interannual SST variability is removed, and it almost disappears if the zonal asymmetry of SST mean state is removed. The results suggest that the zonal asymmetric AIV pattern primarily originates from the zonal asymmetric SST mean state, and it is amplified by the interannual SST variability. The atmospheric convection-circulation feedback plays a key role in connecting the AIV with the mean state precipitation. In both observation and CAM4 simulations, stronger (weaker) convection-circulation feedback is seen in moister (drier) regions. By modulating the mean state precipitation and the
\end{abstract}

Chao He

hechao@mail.iap.ac.cn

1 Institute of Tropical and Marine Meteorology (ITMM), China Meteorological Administration (CMA), Guangzhou, China

2 LASG, Institute of Atmospheric Physics (IAP), Chinese Academy of Sciences (CAS), Beijing, China associated intensity of convection-circulation feedback, the zonal asymmetric SST mean state accounts for the zonal asymmetry of AIV in the subtropical northern hemisphere.

Keywords Interannual variability · Zonal asymmetry · Sea surface temperature $\cdot$ Convection-circulation feedback

\section{Introduction}

The Amplitude of Interannual climate Variability (AIV) over subtropical western North Pacific (WNP) was claimed to be the largest over the subtropical northern hemisphere (Lu 2001; Sui et al. 2007; Wu and Zhou 2008; Chung et al. 2011). The strong interannual variability of atmospheric circulation over WNP has a profound influence on East Asia climate (Zhong et al. 2010), and it plays a crucial role in connecting the tropical Sea Surface Temperature (SST) anomalies with East Asian climate (Zhang et al. 1999; Chang et al. 2000; Chen et al. 2015a). As is widely noted by previous studies, an anomalous anticyclone over WNP favors anomalous water vapor transport into Yangtze River valley (Zhang et al. 1999; Zhou and Yu 2005), leading to disastrous flood such as in the summer of 1998 (Ma et al. 2015).

Although it was claimed that the amplitude of AIV over WNP is the largest among subtropical northern hemisphere, the only metric adopted by previous studies is geopotential height, either at $850 \mathrm{hPa}(\mathrm{Lu} 2001)$ or at $500 \mathrm{hPa}$ (Sui et al. 2007; Wu and Zhou 2008; Chung et al. 2011). As shown in Fig. 1a, the AIV of $850 \mathrm{hPa}$ geopotential height (H850) is much lower in the tropics than in the mid-latitudes, especially it approximates to zero near the equator. Similar results are obtained if $500 \mathrm{hPa}$ geopotential height is used (figure not shown). This contradicts with the common 


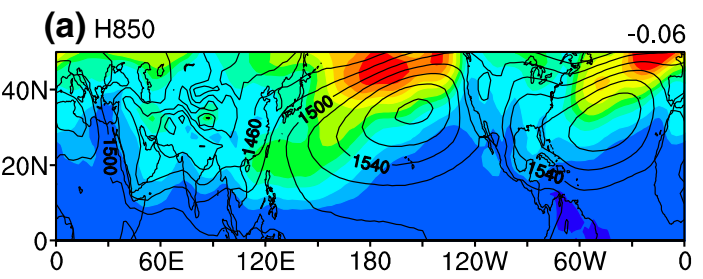

(b) SST

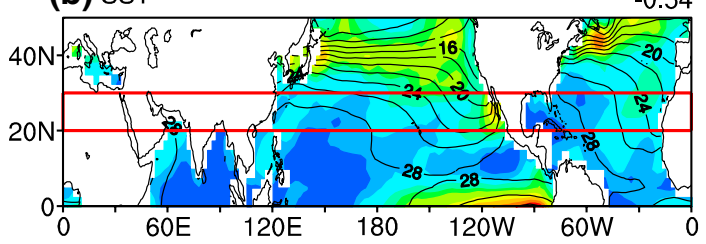

(c) $\mathrm{Pr}$

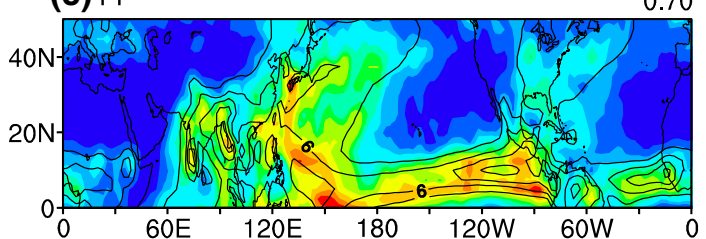

(d) W500

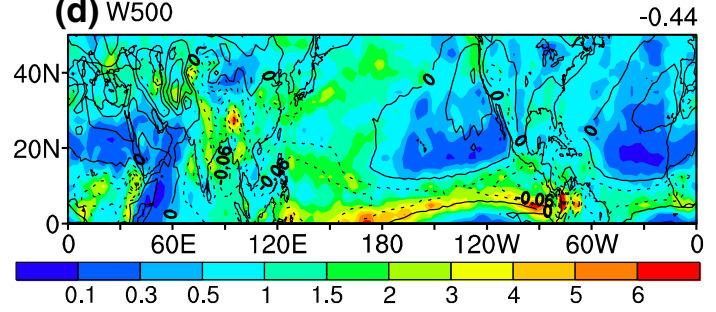

Fig. 1 The AIV (shading) and the mean state (contours) for multiple variables. a $850 \mathrm{hPa}$ geopotential height (unit m), b SST (unit ${ }^{\circ} \mathrm{C}$ ), c precipitation (unit $\mathrm{mm}$ day $^{-1}$ ), d $500 \mathrm{hPa}$ vertical velocity (unit $\mathrm{Pa} \mathrm{s}^{-1}$ ). The AIV shown here is scaled by its domain average and is dimensionless. The pattern correlation coefficient between the AIV and the mean state for each variable is marked on the upper-right corner of each panel

knowledge that the strongest source of interannual climate variability is El Nino-Southern Oscillation (ENSO) which originates in the equatorial Pacific. It may not be suitable to measure the AIV by using geopotential height, and an intercomparison of multiple atmospheric variables is needed to check the robustness of the subtropical AIV pattern.

Great attention has been paid on how WNP climate variability is forced by tropical SST anomalies. Five key oceanic regions are identified to be responsible for the interannual climate variability over WNP. These five regions include the equatorial Pacific Ocean (Chang et al. 2000; Wang et al. 2000, 2013; Xiang et al. 2013), tropical Indian Ocean (Wu et al. 2000; Li et al. 2008; Xie et al. 2009; Wu et al. 2010), tropical Atlantic Ocean (Lu and Dong 2005; Rong et al. 2010; Hong et al. 2014; Chen et al. 2015b), the vicinity of the maritime continent (Lu et al. 2006; Sui et al. 2007; Wu et al. 2009; Chung et al. 2011), and WNP (Wang et al. 2000; Wu et al. 2010; Wang et al. 2013; Xiang et al. 2013). The detailed mechanisms on how the WNP climate is modulated by these five regions are reviewed in He et al. (2015a).

Although a good understanding has been obtained on how WNP climate is forced by SST, it is still not clear why the AIV over WNP is larger than other subtropical regions, The formation mechanism for the spatial pattern of AIV has not been well explained. According to previous studies, two factors residing in SST may be responsible for the pattern of AIV.

First, the pattern of SST mean state, especially its zonal asymmetric pattern. Convection-circulation feedback is a key process which amplifies the interannual climate variability over WNP, i.e., an initial circulation anomaly results in a rainfall anomaly, and the latent heating anomaly associated with the rainfall anomaly in turn enhances the circulation anomaly (Xie et al. 2009; Jin et al. 2013; Xiang et al. 2013; He et al. 2015b). The intensity of the convection-circulation feedback depends on the abundance of mean state precipitation (Huang and Xie 2015), and the mean state precipitation is regulated by the SST (Seager et al. 2003).

Second, the interannual SST variability. The amplitude of SST variability is not uniformly distributed but characterized by a distinct spatial pattern (Fig. 1b). Larger SST variability is not necessarily associated with larger local atmospheric variability, because atmospheric variability is impacted by not only local SST anomaly but also non-local SST anomalies. The complicated relationship between the interannual SST variability and the AIV of the atmosphere calls for in-depth study.

More and more studies begin to pay attention to the response of interannual climate variability to global warming ( $\mathrm{Lu}$ and Fu 2010; Cai et al. 2014; Lee et al. 2014; Zhou et al. 2014; Chen et al. 2016), but the fundamental formation mechanism of the current AIV pattern is yet not well understood. This study aims at answering the following two questions: (1) Is it a robust feature that WNP has a larger AIV than other subtropical regions? (2) How is the AIV pattern in the subtropical northern hemisphere regulated by SST, and what are the relative contributions from the mean state and the interannual variability of SST? The first question can be addressed by observational analysis, and numerical simulations are needed to address the second question.

The rest of this article is organized as follows. The descriptions on the data, model and methods are presented in Sect. 2. Analyses on the observed interannual climate variability is documented in Sect. 3. The relative contributions from the mean state and the interannual variability of SST are demonstrated by model experiments in Sect. 4 . Finally, a summary is presented in Sect. 5 . 


\section{Data, model and methods}

We focus on the boreal summers from 1979 to 2014 in the observational analyses. The SST dataset adopted in this study is the Extended Reconstructed SST version 3 (Smith et al. 2008). The precipitation data adopted in this study include the GPCP (Adler et al. 2003) and CMAP (Xie and Arkin 1997) datasets. The atmospheric geopotential height and vertical velocity are adopted from the datasets of ERAIM (Dee et al. 2011), NCEP1 (Kalnay et al. 1996), and NCEP2 (Kanamitsu et al. 2002). All of the above datasets are referred to as "observation" for brevity. Multiple atmospheric datasets are adopted to address the observational uncertainty. The monthly values for June, July and August are averaged into the seasonal mean in summer, referred to as "JJA".

The atmospheric general circulation model employed in this study is the Community Atmosphere Model version 4 (CAM4) (Neale et al. 2013), under a finite volume dynamic core with a horizontal resolution of $1.9^{\circ}$ in latitude and $2.5^{\circ}$ in longitude. In the control (CTL) simulation, CAM4 is forced by observed interannual varying SST from 1900 to 2000, following the design of Atmospheric Model Intercomparison Project (AMIP) simulation (Gates et al. 1999). The observational SST data used as boundary forcing of CAM4 is created by Hurrell et al. (2008). It is a merged dataset between Hadley Center sea ice and SST dataset version 1 (HadISST1) and optimum interpolation (OI) SST version 2. The model outputs from 1901 to 2000 are used for analyses.

Two sensitivity simulations are also performed with CAM4, by modifying the SST without other changes (Table 1). The interannual variability component of the observational SST is extracted by applying an 8-year highpass Fourier filter. In the "No asymmetry" (NoAsy) simulation, the model is forced by idealized SST which is created by adding the interannual variability component to the zonal mean climatology of SST, so that the interannual SST variability is the same as CTL simulation but the zonal asymmetry of SST mean state is removed. In the "No interannual variability" (NoVar) simulation, the interannual variability of SST is removed, and the model is forced by the climatological annual cycle of SST. These two sensitivity

Table 1 An overview of the simulations performed by CAM4

\begin{tabular}{ll}
\hline Experiment ID & SST forcing field \\
\hline CTL & Observational interannual varying SST \\
NoAsy & $\begin{array}{l}\text { Interannual SST variability component plus zonal } \\
\text { averaged SST mean state (The zonal asymmetry of } \\
\text { SST mean state is removed) }\end{array}$ \\
NoVar & $\begin{array}{c}\text { SST climatology (The interannual SST variability is } \\
\text { removed) }\end{array}$
\end{tabular}

experiments are also integrated for 101 years and the last 100 years are adopted for analyses. The difference between CTL and NoAsy simulations demonstrates the role of zonal asymmetric SST mean state, while the difference between CTL and NoVar simulations demonstrates the effect of interannual SST variability.

The amplitude of interannual variability is measured by the interannual variance, i.e., the variance of the interannual variability component of the time series. All the observational and model time series at all grid points are filtered by an 8-year high-pass Fourier filter before calculating the interannual variance. The decadal oscillations with a period greater than 8 years are removed and the filtered time series contain only interannual variability. The interannual variance of precipitation is investigated, since precipitation has direct societal impacts and its usage is recommended by previous studies (Cai et al. 2014; Huang and Xie 2015). The AIV of circulation is measured in terms of the interannual variance of $500 \mathrm{hPa}$ vertical velocity (W500), in comparison with the interannual variance of $850 \mathrm{hPa}$ geopotential height (H850).

Pattern correlation coefficient is adopted to evaluate the similarity between two fields. The statistic significance is tested based on Student's $t$ distribution, where the degree of freedom is estimated following the method of Leith (1973). The auto-correlation for the spatial patterns of either precipitation or W500 ranges from 0.65 to 0.97 . In this study, the number of grid points for pattern correlation is 3024 , and a rigorous estimate of the degree of freedom is $-0.5 \times \ln (0.97) \times 3024=46$. Therefore, a pattern correlation coefficient exceeding $\pm 0.28( \pm 0.37)$ is considered significant at the $95 \%(99 \%)$ confidence level.

\section{Amplitude of interannual climate variability in observation}

Is the pattern of AIV robust among multiple meteorological variables? Figure $1 \mathrm{c}-\mathrm{d}$ shows the patterns of interannual variance for precipitation and W500, respectively. It is clear that the AIVs are larger over the moister regions, including the Inter-Tropical Convergence Zone (ITCZ), the broad area from South Asia to WNP, and a narrow area over the Gulf of Mexico. The patterns of interannual variance for W500 and precipitation are similar to each other, with a pattern correlation coefficient of 0.63 . In contrast, the interannual variance pattern of H850 (Fig. 1a) is much different from that of precipitation, with a low pattern correlation coefficient of -0.07 . It is more reasonable to measure the AIV of atmospheric circulation in terms of W500 instead of H850 for two reasons. First, the AIV of W500 is a good indicator for the AIV of precipitation. Second, the interannual climate variability over tropics and mid-latitudes are 


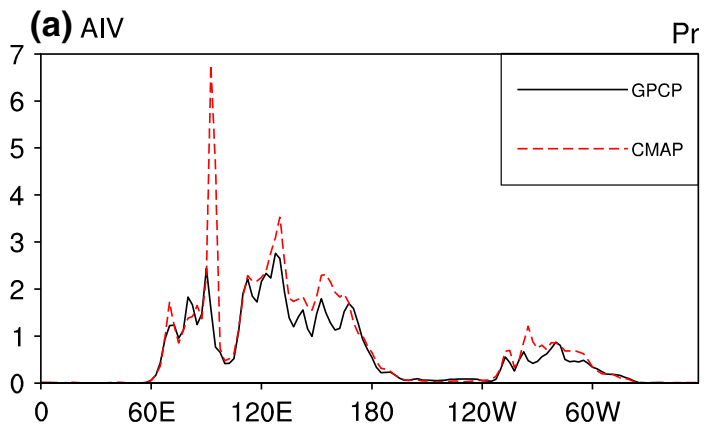

(b) AIV

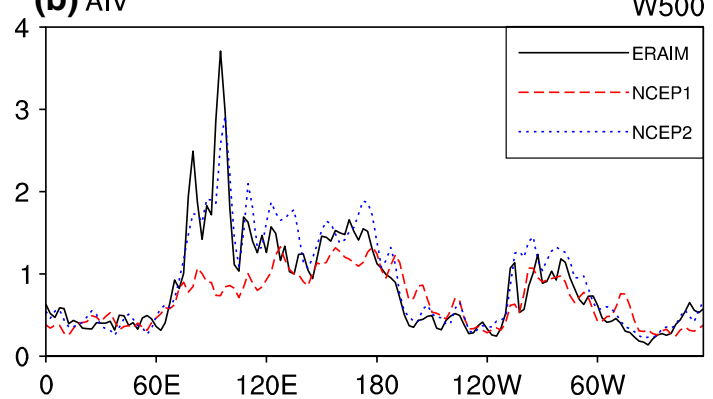

Fig. 2 The zonal profiles of AIV averaged within $20^{\circ} \mathrm{N}-30^{\circ} \mathrm{N}$. a The AIV of precipitation derived from GPCP and CMAP datasets (unit $\mathrm{mm}^{2}$ day $^{-2}$ ). b The AIV of $500 \mathrm{hPa}$ vertical velocity derived from ERAIM, NCEP1 and NCEP2 datasets (unit $10^{-4} \mathrm{~Pa}^{2} \mathrm{~s}^{-2}$ ). The location of the zonal belt within $20^{\circ} \mathrm{N}-30^{\circ} \mathrm{N}$ is shown as the red box in Fig. 1b

both well captured by W500, whereas H850 fails to capture the interannual climate variability over the tropics.

Is the pattern of AIV robust among multiple datasets? Since the major focus of this study is the subtropics, we show the zonal profile of $20^{\circ} \mathrm{N}-30^{\circ} \mathrm{N}$ averaged interannual variance for multiple datasets in Fig. 2. The high interannual precipitation variance from South Asia to WNP is agreed by both GPCP and CMAP datasets (Fig. 2a). A remarkable difference is that CMAP data shows a peak at about $90^{\circ} \mathrm{E}$ over South Asia (the southern slope of Himalayas) but GPCP data does not. The local maximum over the Gulf of Mexico from $100^{\circ} \mathrm{W}$ to $60^{\circ} \mathrm{W}$ is also agreed by both GPCP and CMAP datasets. As seen in the pattern of interannual W500 variance (Fig. 2b), the ERAIM and NCEP2 datasets agree well with each other that the highest interannual W500 variance appears over South Asia instead of WNP. But in NCEP1 dataset, the interannual W500 variance is higher over WNP than South Asia. A comparison between Fig. 2a, b shows that the zonal asymmetric patterns of AIV are similar between precipitation and W500.

How is the pattern of AIV related to the mean state? By comparing the shading with the contours in Fig. 1c, it is clear that larger interannual precipitation variability is located where there is more abundant rainfall. The pattern correlation coefficient between the AIV and the mean state for precipitation is 0.70 , which is statistically significant at the $99 \%$ confidence level according to Student's $t$ test. Similarly, the spatial pattern of AIV is also closely related to the mean state for W500 (Fig. 1d), with a pattern correlation coefficient of -0.44 , also exceeding the $99 \%$ confidence level. These evidences indicate that larger AIV is associated with ascending motion and moister mean state, while smaller AIV is associated with descending motion and drier mean state.

Based on the above observational evidences, there are observational uncertainty on whether the AIV is greater over South Asia or WNP. However, it is robust that the AIV closely follows the mean state precipitation, where larger (smaller) AIV is seen over moister (drier) regions. It is also robust that the AIV over the broad area from South Asia to WNP is greater than other subtropical regions, followed by a secondary peak over the Gulf of Mexico. The AIV is the lowest over the arid regions, especially over eastern part of Pacific and Atlantic Oceans and North Africa.

Why is the AIV greater in moister regions? As implied by previous studies, the intensity of convection-circulation feedback is greater over moister regions (Xie et al. 2009; Jin et al. 2013; Xiang et al. 2013), and stronger local convection-circulation feedback may intensify local AIV. To measure the intensity of the convection-circulation feedback, Fig. 3 shows the regression coefficient of precipitation onto local W500 at interannual time scale. The regression coefficient is greater over moister regions (the ITCZ, South Asia, WNP and western Atlantic Ocean), but smaller over drier regions (eastern subtropical oceans and North Africa). As indicated by the spatial pattern of regression coefficients, greater convection and precipitation anomalies are generated by a unit vertical velocity anomaly at moister regions (Cai et al. 2014; Huang and Xie 2015), and therefore stronger latent heating anomaly is generated by precipitation anomaly. The stronger latent heating anomaly in turn stimulates stronger circulation anomalies. Therefore,

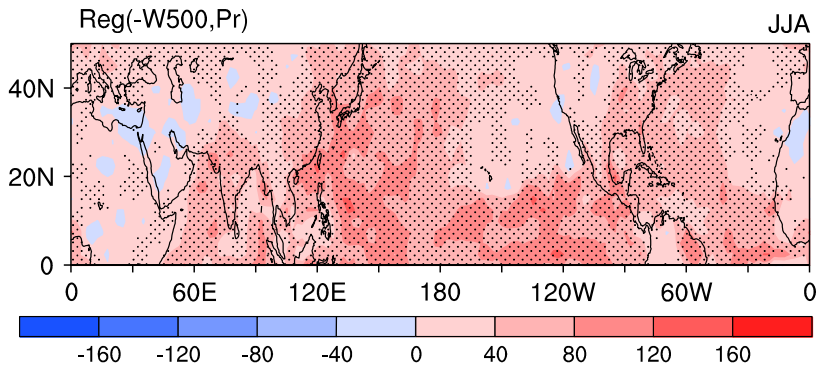

Fig. 3 The observational intensity of convection-circulation feedback measured by the regression coefficient of precipitation onto W500 for the 1979-2014 period [unit $\left(\mathrm{mm} \mathrm{day}^{-1}\right)\left(\mathrm{Pa} \mathrm{s}^{-1}\right)^{-1}$ ]. The regression coefficients are multiplied by -1 , and the regression coefficients significant at the $95 \%$ confidence level are stippled 
the intensity of convection-circulation feedback explains why the AIV is larger over moister regions.

The above observational evidences suggest that the spatially differentiated intensity of convection-circulation feedback plays a role in linking the mean state and AIV patterns. However, interannual SST variability is also crucial for the interannual atmospheric variability. The contribution of SST variability cannot be diagnosed by comparing the observational AIV patterns between SST and atmospheric variables, since precipitation and circulation are impacted by not only local but also remote SST anomalies. To further illustrate the mechanism for the AIV pattern, model simulations are needed.

\section{Relative contributions from mean state and variability of SST}

The observed mean state and AIV are captured by the CTL simulation of CAM4. Consistent with the observed mean state (Fig. 1c), the large AIVs of precipitation over the ITCZ, South Asia, WNP and the Gulf of Mexico are well captured by CAM4 (Fig. 4a). A major discrepancy from the observation is the overestimated AIV over South Asia and the underestimated AIV around the Philippines. Therefore, the zonal asymmetry in CAM4 is slightly weaker within the subtropical Pacific but stronger than observation in the entire subtropical northern hemisphere. The close relationship between the mean state and the AIV of rainfall is captured, with a pattern correlation coefficient of 0.81 , exceeding the $99 \%$ confidence level. The mean state and AIV of W500 are also well captured (Fig. 4b). The correlation coefficients between AIV and mean state for W500 is -0.59 , consistent with the observational feature that higher (lower) AIV of circulation is located at the ascending (descending) region. In all, CAM4 well captures the observed AIV, mean state, and the relationship between AIV and mean state, adding to our confidence in further analyses on the sensitivity simulations.

The role of the zonal asymmetric SST mean state is demonstrated as the difference in interannual variances between CTL and NoAsy simulations (Fig. 5a). Over the subtropical northern hemisphere, the zonal asymmetric SST mean state amplifies the interannual precipitation variance over South Asia, WNP, and the Gulf of Mexico, but damps the AIV over the eastern North Pacific and centraleastern Atlantic Ocean. The AIV of precipitation at the equatorial oceans is damped by the zonal asymmetric mean state, the cause of which is out of the scope of this study. The modeling evidence shows that the zonal asymmetric SST mean state does make a substantial contribution to the zonal asymmetric pattern of AIV over subtropical northern hemisphere. (a) $\operatorname{Pr}$

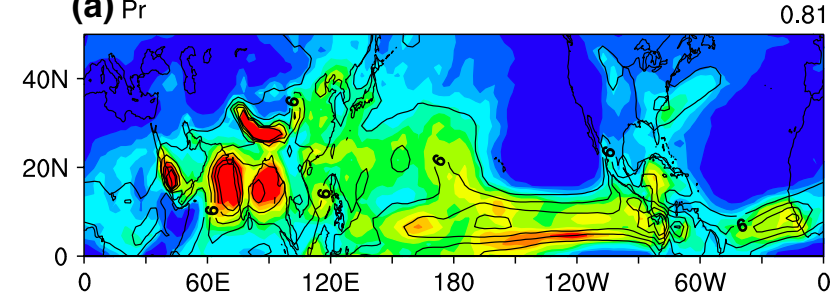

(b) $\mathrm{W} 500$

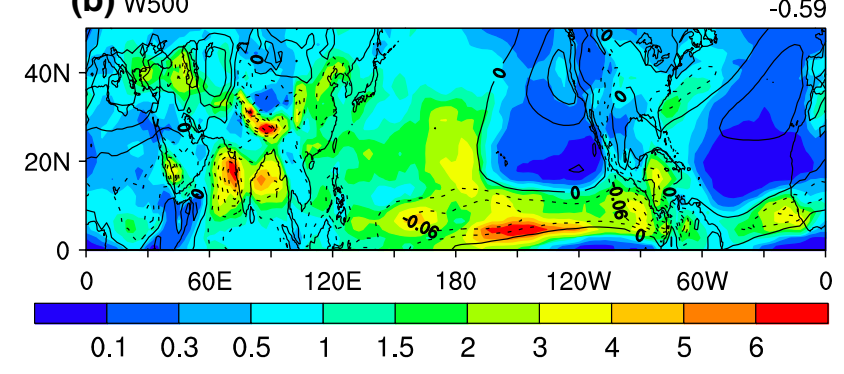

Fig. 4 The AIV (shading) and mean state (contours) in CTL simulation. a Precipitation (unit mm day ${ }^{-1}$ ), b W500 (unit Pa s${ }^{-1}$ ). The AIV shown here is scaled by the domain average and is dimensionless. The pattern correlation coefficient between the mean state and the AIV is marked on the upper-right corner of each panel

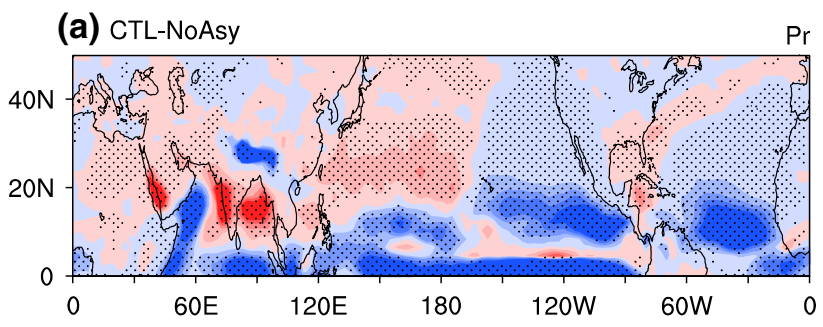

(b) CTL-NoVar

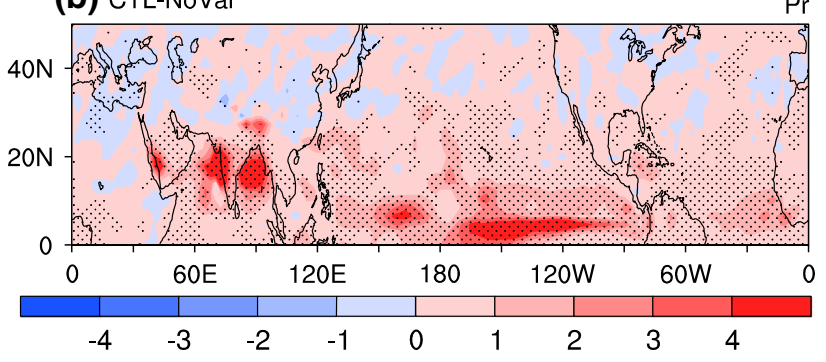

Fig. 5 The differences of the AIV of precipitation between the CTL simulation and the sensitivity simulations (unit $\mathrm{mm}^{2} \mathrm{day}^{-2}$ ). a CTL simulation minus NoAsy simulation. b CTL simulation minus NoVar simulation. The difference in interannual variance statistically significant at the $95 \%$ confidence level is stippled

The role of interannual SST variability is demonstrated as the difference between CTL and NoVar simulations (Fig. 5b). It is clear that the SST variability amplifies the interannual precipitation variance over the deep tropics, especially along the ITCZ, the Arab Sea and the Bay of Bengal. At the subtropics north of $20^{\circ} \mathrm{N}$, the SST variability still amplifies the AIV of precipitation but its effect is 


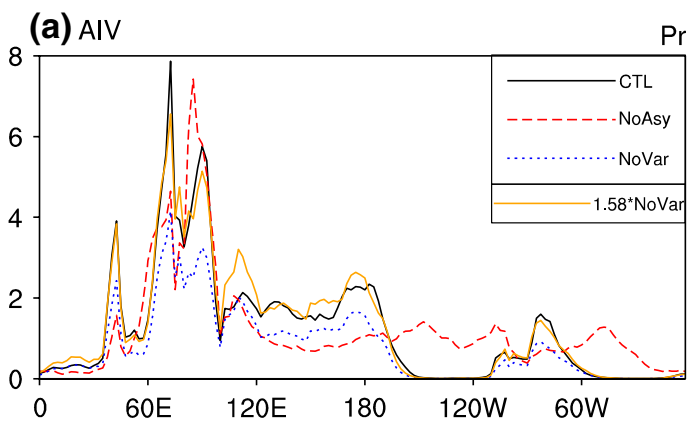

(b) Mean State

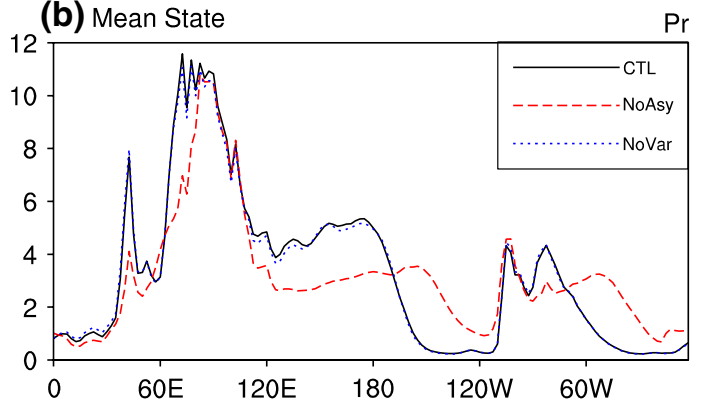

Fig. 6 The zonal profile of the $20^{\circ} \mathrm{N}-30^{\circ} \mathrm{N}$ averaged AIV (a) and mean state (b) of precipitation in the three simulations. In both (a) and (b), the black, red and blue lines are for the CTL, NoAsy, and NoVar simulations, respectively. In (a), the orange line stands for the AIV in the NoVar simulation multiplied by a factor of 1.58

weaker. To focus on the subtropics, the zonal profiles for the $20^{\circ} \mathrm{N}-30^{\circ} \mathrm{N}$ averaged AIV and mean state are shown in Fig. 6.

The CTL simulation is characterized by large AIV from South Asia to WNP, with a secondary peak over tropical Atlantic (black line in Fig. 6a). The CTL simulation more resembles CMAP data that the highest peak is seen over South Asia rather than WNP, which is different from GPCP data. Compared with CTL simulation, the highest AIV of precipitation in NoAsy simulation slightly shifts eastward from $72.5^{\circ} \mathrm{E}$ to $85^{\circ} \mathrm{E}$ (red line in Fig. 6a). Over the broad subtropical regions other than the South Asia, the zonal difference of the AIV almost disappears. The AIV decreases substantially over WNP and the Gulf of Mexico, but increases over eastern Pacific and eastern Atlantic Oceans. In the NoVar simulation (blue line in Fig. 6a), the AIV in precipitation is also characterized by zonal asymmetric pattern but the zonal asymmetry is weaker than the CTL simulation. By regressing the profile of CTL simulation onto NoVar simulation, it is found that if a factor of 1.58 is multiplied on the zonal profile of NoVar simulation (orange line in Fig. 6a), it most closely fits to the CTL simulation. This indicates the role of the SST variability is to amplify the AIV of precipitation by $58 \%$ across the subtropics, which magnifies the zonal asymmetry.
How is the AIV connected to the mean state precipitation in the simulations? As shown in Fig. 6b, the mean state of precipitation in NoVar simulation fits well with CTL simulation, suggesting the interannual variability of SST has no impact on the mean state of rainfall over subtropical northern hemisphere. In the NoAsy simulation, the zonal asymmetry of the mean state precipitation substantially weakens. This is consistent with Seager et al. (2003) that the zonal asymmetric SST amplifies the subtropical anticyclones which favors moist (dry) condition over western (eastern) subtropical oceans. In a moister atmosphere with more mean state precipitation, greater precipitation anomaly can be stimulated by a unit circulation anomaly (Cai et al. 2014; Huang and Xie 2015). Therefore, the weakened asymmetry in the mean state rainfall explains the weakened asymmetry of the AIV across the subtropical basins in NoAsy simulation. Compared with WNP, no substantial decrease of mean state precipitation is seen over South Asia Fig. 6b, since the South Asian area shown in Fig. 6b is dominated by land (see Fig. 1b), and land surface temperature is not artificially modified in NoAsy simulation.

How is the AIV of W500 impacted by the mean state and variability of SST? Does it share similar pattern with precipitation? As shown in the difference between CTL and NoAsy simulations (Fig. 7a), the AIV of W500 increases significantly at the $95 \%$ confidence level over the Bay of Bengal, WNP and the Gulf of Mexico, but decrease significantly over eastern North Pacific and central-eastern North Atlantic. The zonal asymmetry of the SST mean state regulates the zonal asymmetric AIV pattern of not only precipitation but also circulation. As shown in the difference between CTL and NoVar simulations (Fig. 7b), the interannual SST variability significantly amplifies the AIV of W500 over the deep tropics, especially equatorial central Pacific. Compared with the deep tropics, the effect of SST variability is weaker at north of $20^{\circ} \mathrm{N}$.

The $20^{\circ} \mathrm{N}-30^{\circ} \mathrm{N}$ averaged zonal profiles for the interannual W500 variance are displayed in Fig. 8a. Compared with CTL simulation, the zonal asymmetry of AIV of W500 weakens in the oceanic sectors in NoAsy simulation. However, in the NoVar simulation, the zonal asymmetric pattern as seen in CTL simulation is still clear despite of smaller amplitude. Regression of the zonal profiles between CTL and NoVar simulations suggest that, the zonal profile in NoVar simulation well fits the CTL simulation if the former is multiplied by a factor of 1.39 (orange line in Fig. 8a). This suggests the interannual SST variability amplifies the AIV of W500 for $39 \%$ over the subtropical northern hemisphere, and therefore amplifies the existing zonal asymmetry. This value of amplification is slightly smaller than that for the precipitation (Fig. 6a), possibly suggesting the direct role of SST variability on precipitation and its indirect role on W500 through 


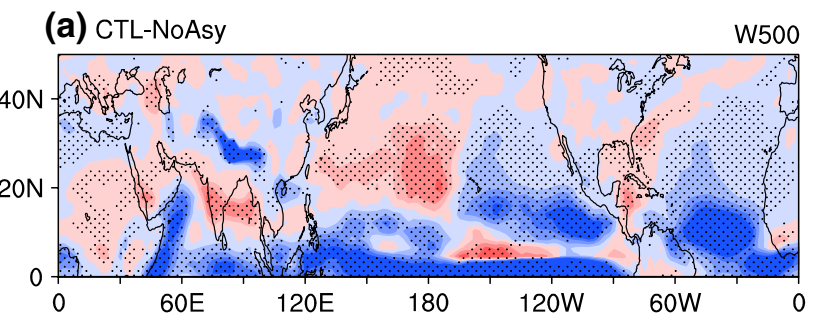

(b) CTL-NoVar

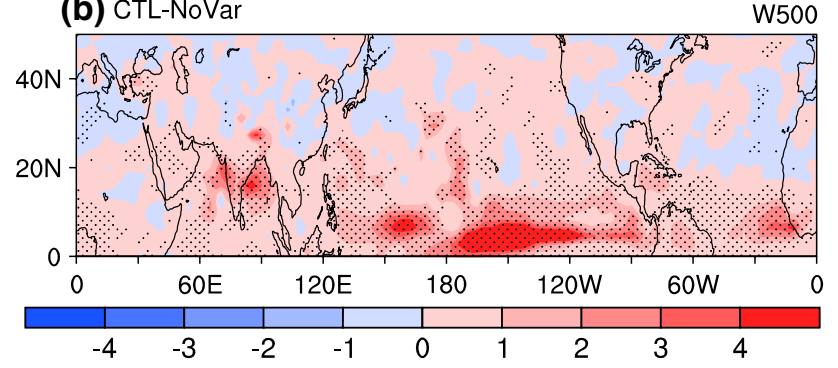

Fig. 7 Same as Fig. 5, but for $500 \mathrm{hPa}$ vertical velocity (unit $10^{-4} \mathrm{~Pa}^{2} \mathrm{~s}^{-2}$ )

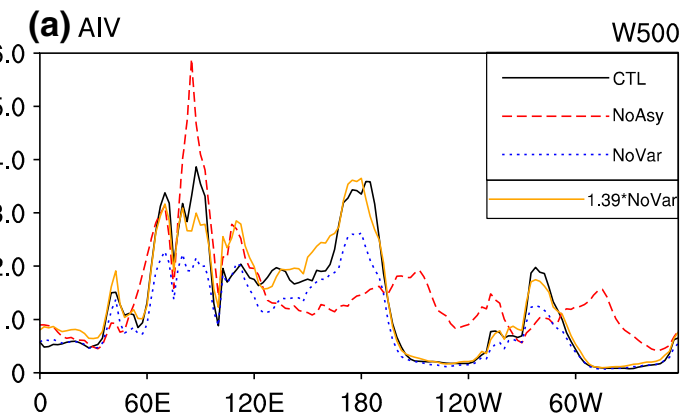

(b) $\operatorname{Reg}(-\mathrm{W} 500, \operatorname{Pr})$

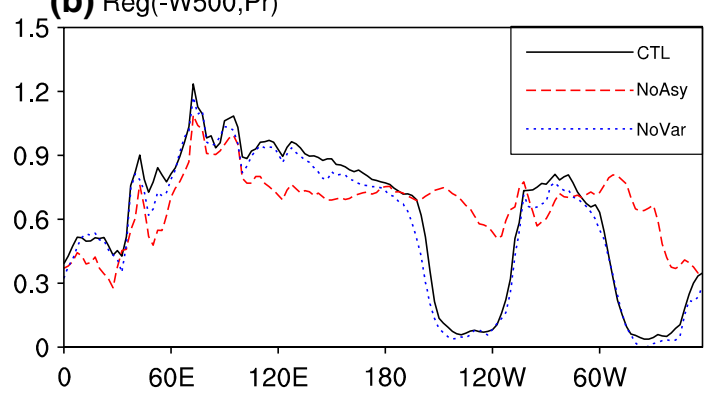

Fig. 8 a The zonal profile of the $20^{\circ} \mathrm{N}-30^{\circ} \mathrm{N}$ averaged AIV of W500 (unit $10^{-4} \mathrm{~Pa}^{2} \mathrm{~s}^{-2}$ ). b The zonal profile of the $20^{\circ} \mathrm{N}-30^{\circ} \mathrm{N}$ averaged regression coefficient of precipitation onto W500 multiplied by -1 [unit $10^{2}\left(\mathrm{~mm} \mathrm{day}^{-1}\right) \cdot\left(\mathrm{Pa} \mathrm{s}^{-1}\right)^{-1}$ ]. In both (a) and (b), the black, red and blue lines are for the CTL, NoAsy, and NoVar simulations, respectively. In (a), the orange line stands for the AIV in the NoVar simulation multiplied by a factor of 1.39

changing the precipitation. In all, the zonal asymmetric AIV in the subtropics is determined by the zonal asymmetry of the SST mean state, whereas the variability of SST plays a secondary role in amplifying the zonal asymmetry.
To explain how the AIV of W500 is regulated by SST, the $20^{\circ} \mathrm{N}-30^{\circ} \mathrm{N}$ averaged regression coefficients of precipitation onto W500 at interannual timescale are shown in Fig. 8b. In the CTL simulation, the convection-circulation feedback is strong over South Asia, WNP and the Gulf of Mexico, but weak in the eastern Pacific and eastern Atlantic. In the NoAsy simulation, the zonal asymmetry in the intensity of convection-circulation feedback weakens substantially, and little difference is seen between the western part and eastern part of the oceans. This is caused by the weakened zonal asymmetry of the mean state precipitation (see Fig. 6b). In the NoVar simulation, the intensity of convection-circulation feedback closely resembles that of the CTL simulation, consistent with the high consistency of precipitation mean state between these two simulations (see Fig. 6b). The above evidences suggest that intensity of convection-circulation feedback highly depends on the precipitation mean state, and the spatially differentiated intensities of convection-circulation feedback are responsible for the AIV pattern of atmospheric circulation.

Based on the above numerical simulations, it can be concluded that the zonal asymmetry in the AIV over the subtropical northern hemisphere is determined by the zonal asymmetry of SST mean state, while the SST variability plays a secondary role in amplifying the zonal asymmetry. Although the SST variability has substantial effect on AIV in the equatorial regions such as ITCZ, its effect on the subtropical northern hemisphere is limited. The relative importance of the mean state and the variability of SST differs between tropics and subtropics.

\section{Conclusion and discussion}

The amplitude of interannual climate variability is characterized by a distinct spatial pattern over the subtropical northern hemisphere. The robustness of its pattern is evaluated in terms of different meteorological variables in multiple datasets. The formation mechanism for the AIV pattern is investigated through sensitivity simulations performed by CAM4. By removing the zonal asymmetric mean state and the interannual variability of SST, the relative roles of zonal asymmetric mean state and the interannual variability of SST are demonstrated. The major conclusions are summarized as follows.

1. It is a robust feature that the interannual climate variability is the strongest over the broad area from South Asia to WNP over the subtropical northern hemisphere, followed by a secondary local peak over the Gulf of Mexico. The AIV pattern of precipitation is consistent with that of circulation in terms of W500. The pattern of AIV depends strongly on the mean state pre- 
cipitation, and higher (lower) AIV is seen over moister (drier) regions. Our results show that the W500 is more suitable to measure the AIV of circulation compared with geopotential height, since the former well captures the tropical variability and the connection of circulation to precipitation.

2. The zonal asymmetric pattern of AIV over the subtropical northern hemisphere is dominated by the zonal asymmetry of SST mean state, and it is amplified by the interannual variability of SST. The zonal asymmetry of the AIV disappears if the zonal asymmetric SST mean state is removed, and it is weakened if the SST variability is removed. The interannual variability of SST plays a role in amplifying the AIV of the precipitation (by $58 \%$ ) and circulation (by $39 \%$ ), and it therefore amplifies the zonal asymmetry of the AIV.

3. Convection-circulation feedback dependent on the mean state is the key physical process connecting the mean state with AIV. Over the subtropical northern hemisphere, the zonal asymmetric pattern of AIV is well explained by the zonal asymmetric intensity of convection-circulation feedback, where stronger AIV is associated with stronger local convection-circulation feedback. In both observation and model simulations, the intensity of convection-circulation feedback is stronger (weaker) over moister (drier) regions. By modulating the zonal distribution of the mean state precipitation, the zonal asymmetric SST mean state results in the zonal asymmetric intensity of convection-circulation feedback, and accounts for the AIV pattern over the subtropical northern hemisphere.

\begin{abstract}
Acknowledgments The authors wish to express thanks to the two anonymous reviewers for their constructive comments and suggestions which improved the quality of this paper. We also wish to acknowledge NOAA and NCAR who offered us observational data (http://www.esrl.noaa.gov/psd/data) and CAM4 (http://www2. cesm.ucar.edu). This work was jointly supported by National Basic Research Program of China (2014CB953901), National Natural Science Foundation of China (41505067, 41575043, 41205069, 41375095), and Natural Science Foundation of Guangdong Province of China (2014A030310432).
\end{abstract}

Open Access This article is distributed under the terms of the Creative Commons Attribution 4.0 International License (http://creativecommons.org/licenses/by/4.0/), which permits unrestricted use, distribution, and reproduction in any medium, provided you give appropriate credit to the original author(s) and the source, provide a link to the Creative Commons license, and indicate if changes were made.

\section{References}

Adler RF, Huffman GJ, Chang A et al (2003) The version-2 global precipitation climatology project (GPCP) monthly precipitation analysis (1979-present). J Hydrometeorol 4(6):1147-1167. doi:10.1175/1525-7541(2003)004<1147:tvgpcp>2.0.co;2
Cai W, Borlace S, Lengaigne M et al (2014) Increasing frequency of extreme El Nino events due to greenhouse warming. Nat Clim Change 4(2):111-116. doi:10.1038/nclimate2100

Chang CP, Zhang YS, Li T (2000) Interannual and interdecadal variations of the East Asian summer monsoon and tropical Pacific SSTs. Part I: roles of the subtropical ridge. J Clim 13(24):4310 4325. doi:10.1175/1520-0442(2000)013<4310:iaivot>2.0.co;2

Chen Z, Wen Z, Wu R, Lin X, Wang J (2015a) Relative importance of tropical SST anomalies in maintaining the Western North Pacific anomalous anticyclone during El Niño to La Niña transition years. Clim Dynam. doi:10.1007/s00382-015-2630-1

Chen W, Lee J-Y, Lu R, Dong B, Ha K-J (2015b) Intensified impact of tropical Atlantic SST on the western North Pacific summer climate under a weakened Atlantic thermohaline circulation. Clim Dynam 45(7-8):2033-2046. doi:10.1007/s00382-014-2454-4

Chen W, Lee J-Y, Ha K-J, Yun K-S, Lu R (2016) Intensification of the Western North Pacific Anticyclone response to the short decaying El Niño event due to greenhouse warming. J Clim. doi:10.1175/jcli-d-15-0195.1

Chung P-H, Sui C-H, Li T (2011) Interannual relationships between the tropical sea surface temperature and summertime subtropical anticyclone over the western North Pacific. J Geophys Res Atmos 116:D13111. doi:10.1029/2010jd015554

Dee DP, Uppala SM, Simmons AJ et al (2011) The ERA-Interim reanalysis: configuration and performance of the data assimilation system. Q J Roy Meteorol Soc 137(656):553-597. doi:10.1002/qj.828

Gates WL, Boyle JS, Covey C et al (1999) An overview of the results of the Atmospheric Model Intercomparison Project (AMIP I). Bull Am Meteorol Soc 80(1):29-55. doi:10.1175/1520-0477(1999)080<0029:aootro $>2.0 . c 0 ; 2$

He C, Zhou T, Wu B (2015a) The key oceanic regions responsible for the interannual variability of the western North Pacific subtropical high and associated mechanisms. J Meteorol Res 29(4):562575. doi:10.1007/s13351-015-5037-3

He B, Yang S, Li Z (2015b) Role of atmospheric heating over the South China Sea and western Pacific regions in modulating Asian summer climate under the global warming background. Clim Dynam 1-12. doi:10.1007/s00382-015-2739-2

Hong C-C, Chang T-C, Hsu H-H (2014) Enhanced relationship between the tropical Atlantic SST and the summertime western North Pacific subtropical high after the early 1980s. J Geophys Res Atmos 119 (7):2013JD021394. doi:10.1002/2013jd021394

Huang P, Xie S-P (2015) Mechanisms of change in ENSO-induced tropical Pacific rainfall variability in a warming climate. Nat Geosci Adv. doi:10.1038/ngeo2571

Hurrell JW, Hack JJ, Shea D, Caron JM, Rosinski J (2008) A new sea surface temperature and sea ice boundary dataset for the Community Atmosphere Model. J Clim 21(19):5145-5153. doi:10.1 175/2008jcli2292.1

Jin Q, Yang X-Q, Sun X-G, Fang J-B (2013) East Asian summer monsoon circulation structure controlled by feedback of condensational heating. Clim Dynam 41(7-8):1885-1897. doi:10.1007/ s00382-012-1620-9

Kalnay E, Kanamitsu M, Kistler R et al (1996) The NCEP/NCAR 40-year reanalysis project. B Am Meteorol Soc 77(3):437-471. doi:10.1175/1520-0477(1996)077<0437:tnyrp>2.0.co;2

Kanamitsu M, Ebisuzaki W, Woollen J, Yang SK, Hnilo JJ, Fiorino M, Potter GL (2002) NCEP-DOE AMIP-II reanalysis (R-2). B Am Meteorol Soc 83(11):1631-1643. doi:10.1175/bams-83-11-1631

Lee J-Y, Wang B, Seo K-H, Kug J-S, Choi Y-S, Kosaka Y, Ha K-J (2014) Future change of northern hemisphere summer tropical-extratropical teleconnection in CMIP5 Models*. J Clim 27(10):3643-3664. doi:10.1175/jcli-d-13-00261.1

Leith CE (1973) The standard error of time-average estimates of climatic means. J Appl Meteorol 12(6):1066-1069. doi:10.1175/1520-0450(1973)012<1066:tseota $>2.0 . c 0 ; 2$ 
Li SL, Lu J, Huang G, Hu KM (2008) Tropical Indian Ocean basin warming and East Asian summer monsoon: a multiple AGCM study. J Clim 21(22):6080-6088. doi:10.1175/2008jcli2433.1

Lu R (2001) Interannual variability of the summertime North Pacific subtropical high and its relation to atmospheric convection over the warm pool. J Meteorol Soc Jpn 79(3):771-783. doi:10.2151/ jmsj.79.771

Lu RY, Dong BW (2005) Impact of Atlantic sea surface temperature anomalies on the summer climate in the western North Pacific during 1997-1998. J Geophys Res Atmos 110:D16102. doi:10.1 029/2004jd005676

Lu R, Fu Y (2010) Intensification of East Asian summer rainfall interannual variability in the twenty-first century simulated by 12 CMIP3 coupled models. J Clim 23(12):3316-3331. doi:10.117 $5 / 2009$ jcli3130.1

Lu R, Li Y, Dong B (2006) External and internal summer atmospheric variability in the Western North Pacific and East Asia. J Meteorol Soc Jpn Ser II 84(3):447-462. doi:10.2151/jmsj.84.447

Ma J, Wang H, Fan K (2015) Dynamic downscaling of summer precipitation prediction over China in 1998 using WRF and CCSM4. Adv Atmos Sci 32(5):577-584. doi:10.1007/s00376-014-4143-y

Neale RB, Richter J, Park S, Lauritzen PH, Vavrus SJ, Rasch PJ, Zhang M (2013) The mean climate of the Community Atmosphere Model (CAM4) in forced SST and fully coupled experiments. J Clim 26(14):5150-5168. doi:10.1175/jcli-d-12-00236.1

Rong X, Zhang R, Li T (2010) Impacts of Atlantic sea surface temperature anomalies on Indo-East Asian summer monsoon-ENSO relationship. Chin Sci Bull 55(22):2458-2468. doi:10.1007/ s11434-010-3098-3

Seager R, Murtugudde R, Naik N, Clement A, Gordon N, Miller J (2003) Air-sea interaction and the seasonal cycle of the subtropical anticyclones. J Clim 16(12):1948-1966. doi:10.1175/1520-0442(2003)016<1948:aiatsc >2.0.co;2

Smith TM, Reynolds RW, Peterson TC, Lawrimore J (2008) Improvements to NOAA's historical merged land-ocean surface temperature analysis (1880-2006). J Clim 21(10):2283-2296. doi:10.11 75/2007jcli2100.1

Sui CH, Chung PH, Li T (2007) Interannual and interdecadal variability of the summertime western North Pacific subtropical high. Geophys Res Lett 34(11):L11701. doi:10.1029/2006g1029204

Wang B, Wu RG, Fu XH (2000) Pacific-East Asian teleconnection: how does ENSO affect East Asian climate? J Clim 13(9):1517-1536. doi:10.1175/1520-0442(2000)013<1517:PEATHD>2.0.CO;2
Wang B, Xiang B, Lee J-Y (2013) Subtropical high predictability establishes a promising way for monsoon and tropical storm predictions. Proc Natl Acad Sci 110(8):2718-2722. doi:10.1073/ pnas. 1214626110

Wu B, Zhou TJ (2008) Oceanic origin of the interannual and interdecadal variability of the summertime western Pacific subtropical high. Geophys Res Lett 35(13):L13701. doi:10.1029/200 $8 \mathrm{~g} 1034584$

Wu G, Liu P, Liu Y, Li W (2000) Impacts of the sea surface temperature anomaly in the Indian Ocean on the subtropical anticyclone over the western Pacific-two-stage thermal adaptation in the atmosphere. Acta Meteorol Sin 58(5):513-522 (in Chinese)

Wu B, Zhou TJ, Li T (2009) Seasonally evolving dominant interannual variability modes of East Asian climate. J Clim 22(11):2992-3005. doi:10.1175/2008jcli2710.1

Wu B, Li T, Zhou TJ (2010) Relative contributions of the Indian Ocean and local SST anomalies to the maintenance of the western north Pacific anomalous anticyclone during the El Nino decaying summer. J Clim 23(11):2974-2986. doi:10.1175/2010jcli3300.1

Xiang B, Wang B, Yu W, Xu S (2013) How can anomalous western North Pacific Subtropical High intensify in late summer? Geophys Res Lett 40(10):2349-2354. doi:10.1002/grl.50431

Xie PP, Arkin PA (1997) Global precipitation: a 17-year monthly analysis based on gauge observations, satellite estimates, and numerical model outputs. Bull Am Meteorol Soc 78(11):25392558. doi:10.1175/1520-0477(1997)078<2539:gpayma >2.0.co;2

Xie SP, Hu KM, Hafner J, Tokinaga H, Du Y, Huang G, Sampe T (2009) Indian Ocean capacitor effect on Indo-western Pacific climate during the summer following El Nino. J Clim 22(3):730747. doi:10.1175/2008jcli2544.1

Zhang R, Akimasa S, Masahide K (1999) A diagnostic study of the impact of El Nino on the precipitation in China. Adv Atmos Sci 16(2):229-241. doi:10.1007/bf02973084

Zhong Z, Wang X, Min J (2010) Testing the influence of western Pacific subtropical high. Theor Appl Climatol 100(1-2):67-78. doi:10.1007/s00704-009-0166-1

Zhou TJ, Yu RC (2005) Atmospheric water vapor transport associated with typical anomalous summer rainfall patterns in China. J Geophys Res Atmos 110:D08104. doi:10.1029/2004jd005413

Zhou Z-Q, Xie S-P, Zheng X-T, Liu Q, Wang H (2014) Global warming-induced changes in El Niño teleconnections over the North Pacific and North America. J Clim 27(24):9050-9064. doi:10.1175/jcli-d-14-00254.1 